\title{
Development of Spontaneous Miniature EPSCs in Mouse AVCN Neurons During a Critical Period of Afferent-Dependent Neuron Survival
}

Yong Lu, Julie A. Harris and Edwin W. Rubel

J Neurophysiol 97:635-646, 2007. First published Nov 1, 2006; doi:10.1152/jn.00915.2006

You might find this additional information useful...

This article cites 49 articles, 18 of which you can access free at:

http://jn.physiology.org/cgi/content/full/97/1/635\#BIBL

Updated information and services including high-resolution figures, can be found at:

http://jn.physiology.org/cgi/content/full/97/1/635

Additional material and information about Journal of Neurophysiology can be found at: http://www.the-aps.org/publications/jn

This information is current as of February 22, 2007. 


\title{
Development of Spontaneous Miniature EPSCs in Mouse AVCN Neurons During a Critical Period of Afferent-Dependent Neuron Survival
}

\author{
Yong Lu, Julie A. Harris, and Edwin W. Rubel \\ Virginia Merrill Bloedel Hearing Research Center, Department of Otolaryngology-Head and Neck Surgery, University of Washington, \\ Seattle, Washington
}

Submitted 28 August 2006; accepted in final form 26 October 2006

Lu Y, Harris JA, Rubel EW. Development of spontaneous miniature EPSCs in mouse AVCN neurons during a critical period of afferentdependent neuron survival. J Neurophysiol 97: 635-646, 2007. First published November 1, 2006; doi:10.1152/jn.00915.2006. During a critical period prior to hearing onset, cochlea ablation leads to massive neuronal death in the mouse anteroventral cochlear nucleus (AVCN), where cell survival is believed to depend on glutamatergic input. We investigated the development of spontaneous miniature excitatory postsynaptic currents (mEPSCs) in AVCN neurons using whole cell patch-clamp techniques during [postnatal day 7 (P7)] and after (P14, P21) this critical period. We also examined the effects of unilateral cochlea ablation on mEPSC development. The two main AVCN neuron types, bushy and stellate cells, were distinguished electrophysiologically. Bushy cell mEPSCs became more frequent and faster between P7 and P14/P21 but with little change in amplitude. Dendritic filtering of mEPSCs was not detected as indicated by the lack of correlation between 10 and $90 \%$ rise times and decay time constants. Seven days after cochlea ablation at P7 or P14, mEPSCs in surviving bushy cells were similar to controls, except that rise and decay times were positively correlated $(R=0.31$ and 0.14 for surgery at P7 and $\mathrm{P} 14$, respectively). Consistent with this evidence for a shift of synaptic activity from the somata to the dendrites, SV2 staining (a synaptic vesicle marker) forms a ring around somata of control but not experimental bushy cells. In contrast, mEPSCs of stellate cells showed few significant changes over these ages with or without cochlea ablation. Taken together, mEPSCs in mouse AVCN bushy cells show dramatic developmental changes across this critical period, and cochlea ablation may lead to the emergence of excitatory synaptic inputs impinging on bushy cell dendrites.

\section{N T R O D U C T I O N}

Synaptic activity has two basic forms: evoked and spontaneous. For the auditory system, evoked synaptic activity refers to transmission that occurs in response to acoustic stimuli from the environment. Spontaneous activity, defined here as synaptic responses when there is no sound stimulation, can be further divided into two categories: action potential-dependent and -independent. Action potential-dependent spontaneous activity, elicited by the invasion of action potentials into the presynaptic terminal, can be as large in size as evoked synaptic responses due to the release of many transmitter vesicles. In contrast, action potential-independent synaptic transmission gives rise to small postsynaptic responses (miniature events). These responses are mostly due to the release of a single transmitter vesicle that may reside in a different pool than the

Address for reprint requests and other correspondence: E. W. Rubel, Virginia Merrill Bloedel Hearing Research Center, University of Washington, Box 357923, Seattle, WA 98195 (E-mail: rubel@u.washington.edu). ones responsible for evoked release (Frerking et al. 1997; Sara et al. 2005).

Spontaneous activity in developing neurons is important in maintaining cell survival in the visual system (Catsicas et al. 1992; Chytrova and Johnson 2004; Galli-Resta et al. 1993), and some studies suggest that this may be due to neurotrophic factors co-released during neurotransmission (reviewed in Altar and DiStefano 1998; Davies 1994). Similarly, in the auditory system, conductive hearing loss does not result in cell death in the cochlear nucleus of chickens (Tucci et al. 1987) or monkeys (Doyle and Webster 1991), indicating that spontaneous activity originating from the hair cells or ganglion neurons may be sufficient to maintain central auditory neurons. Interestingly, conductive hearing loss leads to an increase in excitatory responses of ventral cochlear nucleus to sound stimuli given to the contralateral ear, and the spontaneous firing rate of those neurons increases (Sumner et al. 2005). Roles of spontaneous synaptic activity in the auditory system also have been implicated in studies using deaf animals. Single-unit recordings from the auditory nerve in deaf cats showed that spontaneous spikes exist, although hair cells are lacking and most ganglion cells degenerate (Ryugo et al. 1998). These studies did not distinguish between action-potential-dependent and -independent spontaneous synaptic activity and may include both.

Since miniature synaptic events were first observed at neuromuscular junctions (Fatt and Katz 1950, 1952), they have been considered as nonfunctional neuronal activity due to their randomness of occurrence and small amplitude. This view has been challenged recently (reviewed in Otsu and Murphy 2003). Sharma and Vijayaraghavan (2003) provided evidence showing that miniature activity can be regulated by nicotinic receptors on the presynaptic terminals to such a level that elicits action potentials in the postsynaptic neuron, influencing signaling across synapses. Miniature synaptic activity is able to maintain dendritic spines of hippocampal neurons via activation of AMPA receptors (McKinney et al. 1999) and regulate dendritic protein synthesis in cultured hippocampal neurons (Sutton et al. 2004). These studies suggest that miniature synaptic activity may play important roles that have been poorly understood. Whether miniature synaptic activity plays any roles in central auditory neurons is unknown.

In both birds and mammals, deprivation of auditory inputs in young animals results in many changes in the structure and function of cochlear nucleus neurons, followed by neuronal

\footnotetext{
The costs of publication of this article were defrayed in part by the payment of page charges. The article must therefore be hereby marked "advertisement" in accordance with 18 U.S.C. Section 1734 solely to indicate this fact.
} 
death (reviewed in Harris and Rubel 2006; Rubel and Fritzsch 2002). Deprivation of auditory inputs is done either by cochlea removal or pharmacological blockage of action potential-dependent neurotransmission at the cochlear nucleus. The same manipulations, however, do not lead to significant cell death in older animals. Thus there exists a critical period during which survival of cochlear nucleus neurons is dependent on, and after which cell survival is independent of, these excitatory inputs. This critical period seems to correlate with the events leading to the onset of hearing (mice, Mostafapour et al. 2000, 2002; gerbils, Hashisaki and Rubel 1989; Tierney et al. 1997; ferrets, Moore 1990). For example, unilateral destruction of the cochlea in mice at or before the age of P11 results in apoptoticlike cell death of $30-70 \%$ of AVCN bushy cells on the side ipsilateral to the surgery. If the surgery is performed at or later than P14, no significant cell death is observed (Mostafapour et al. 2000).

The mechanisms underlying the critical period have recently been explored, but the results remain largely inconclusive (Harris et al. 2005; Mostafapour et al. 2000, 2002). Although the morphological development of excitatory synapses at AVCN across this critical period has been studied in detail (Limb and Ryugo 2000), corresponding physiological development of the synapses has not been carefully studied. Furthermore, after being deprived of excitatory glutamatergic inputs from the auditory nerve, surviving bushy cells show compensatory structural changes such as reinnervation by nearby terminals (Gentschev and Sotelo 1973) or by synaptogenesis (Benson et al. 1997) and increased nonauditory inputs (Trune and Morgan 1988). However, alterations in functional synaptic transmission at these synapses have not been explored. Here we examined development of spontaneous miniature excitatory postsynaptic currents (mEPSCs) in mouse AVCN neurons (bushy and stellate cells) at ages P7, P14, and $\mathrm{P} 21$ and further examined mEPSCs in AVCN neurons 7 days after cochlea ablation performed at P7 or P14.

\section{METHODS}

\section{Slice preparation and electrophysiological recording}

Brain stem slices (200-250 $\mu \mathrm{m}$ thickness) were prepared from C57BL/6 mice at ages P7, P14, and P21, using methods modified from Tzounopoulos et al. (2004) and Brew and Forsythe (1995). Briefly, after decapitation, a brain block containing the brain stem and the cerebellum was dissected out in ice-cold bicarbonate-buffered solution containing (in mM) 230 sucrose, $3 \mathrm{KCl}, 1.2 \mathrm{KH}_{2} \mathrm{PO}_{4}, 20$ $\mathrm{NaHCO}_{3}, 1.2 \mathrm{CaCl}_{2}, 5 \mathrm{MgSO}_{4}, 3 \mathrm{HEPES}$, and 10 dextrose with $\mathrm{pH}$ of 7.4 and osmolarity around $290 \mathrm{mOsm} / \mathrm{l}$. The brain block was then glued to a vibratome platform (Technical Products, Saint Louis, MO), which was filled with the same solution as in the preceding text, and four to eight coronal slices containing the cochlear nucleus were obtained.

For recordings, slices were transferred to a $0.5-\mathrm{ml}$ chamber mounted on a Zeiss Axioskop FS (Zeiss, Germany) with a $\times 40$ water-immersion objective and infrared, differential interference contrast optics and continuously superfused with artificial cerebrospinal fluid (ACSF) at a rate of 2-3 ml/min. The ACSF contained (in $\mathrm{mM}$ ) $130 \mathrm{NaCl}, 3 \mathrm{KCl}, 1.2 \mathrm{KH}_{2} \mathrm{PO}_{4}, 20 \mathrm{NaHCO}_{3}, 2.4 \mathrm{CaCl}_{2}, 1.3 \mathrm{MgSO}_{4}$, 3 HEPES, and 10 dextrose and was constantly gassed with $95 \%$ $\mathrm{O}_{2}-5 \% \mathrm{CO}_{2}$, with $\mathrm{pH}$ of 7.4 and osmolarity $\sim 290 \mathrm{mOsm} / \mathrm{l}$. All recordings were performed at a temperature of $34-36^{\circ} \mathrm{C}$, controlled by a feedback temperature controller (Warner Instrument, Hamden,
CT). Patch pipettes were pulled to 1-2 $\mu \mathrm{m}$ tip diameter using calibrated $(75 \mu \mathrm{l})$ glass (VWR, West Chester, PA) and a vertical pipette puller (David Kopf Instruments, Tujunga, CA) and coated with silicone elastomer (Sylgard; Dow Corning, Midland, MI). Electrodes had resistances between 3 and $7 \mathrm{M} \Omega$ when filled with an internal solution containing (in $\mathrm{mM}$ ) $140 \mathrm{~K}$-gluconate, $4.5 \mathrm{MgCl}_{2}$, 4.4 trisphosphocreatine, 9 HEPES, 5 EGTA, 4 Na-ATP, and 0.3 tris-GTP, $\mathrm{pH} 7.3$ adjusted by $\mathrm{KOH}(1 \mathrm{M})$, and osmolarity of $\sim 290 \mathrm{mOsm} / 1$. A liquid junction potential of $10 \mathrm{mV}$ was corrected.

Voltage-clamp experiments were performed with an AxoPatch 200B and current-clamp experiments with an AxoClamp 2B amplifier (Molecular Devices, Union City, CA). Development of firing properties of AVCN neurons was examined using data obtained with the AxoClamp 2B amplifier. The fast current-clamp configuration of the AxoPatch 200B was also used to examine firing properties to determine cell types before acquiring voltage-clamp data, but currentclamp data obtained using the AxoPatch 200B were not included in analysis of firing properties because of known distortions of action potentials by the patch-clamp amplifier (Magistretti et al. 1996). Series resistance was compensated by $80-90 \%$ in voltage-clamp recordings. Data were low-pass filtered at $5-10 \mathrm{kHz}$ and digitized with an ITC-16 (Instrutech, Port Washington, NY) at 20-50 kHz for both on and off-line analysis. Data acquisition was done using Axograph software, version 4.5 (Molecular Devices).

All chemicals and drugs were obtained from Sigma (St Louis, MO) except SR 95531 hydrobromide (gabazine) and sucrose, which were obtained from Tocris (Ballwin, MO) and B.J. Baker (Phillipsburg, NJ), respectively. Drugs were bath-applied.

\section{Recording and analysis of $m E P S C s$}

Immediately after obtaining whole cell configuration, firing patterns in response to current injection were examined under the fast currentclamp configuration to determine cell types; bushy cells fire one to three brief spikes in response to prolonged depolarizing current injections, whereas stellate cells fire spikes throughout the duration. Recording mode was then switched to voltage clamp, and spontaneous activity was chart-recorded at a holding potential of $-60 \mathrm{mV}$. Besides glutamatergic excitatory inputs from the auditory nerve, bushy cells also receive inhibitory inputs from a variety of sources including vertical neurons in the dorsal cochlear nucleus, the trapezoid nucleus, and the superior paraolivary nucleus. Stellate cells also receive inhibitory inputs from vertical neurons as well as local interneurons. Glycine is the major inhibitory transmitter at these synapses (reviewed in Ferragamo and Oertel 2001). Spontaneous excitatory postsynaptic currents (sEPSCs) were isolated in the presence of strychnine $(1 \mu \mathrm{M})$ and gabazine $(10 \mu \mathrm{M})$, which block glycinergic and GABAergic responses, respectively. Adding tetrodotoxin, a voltage-gated sodium channel blocker, does not change sEPSCs at mouse AVCN synapses, indicating that sEPSCs represent miniature EPSCs (mEPSCs) (Oleskevich and Walmsley 2002).

To detect mEPSCs, we slid a template through the chart recordings. The parameters of the template, including amplitude, $10-90 \%$ rise time, and decay time constant (tau), were defined based on an average of real events as well as on previous reports for the same type of neurons (Gardner et al. 1999). The detection threshold is 2.5 to 4 times of the noise SD. Statistics were performed using Excel (Microsoft, Redmond, WA) and Statview (Abacus Concepts, Berkeley, CA), and graphs were made in Igor (Wavemetrics, Lake Oswego, OR). Means \pm SD are reported.

\section{Surgery: cochlear ablation}

The procedures were the same as reported previously (Mostafapour et al. 2000, 2002). Mice were anesthetized using inhaled isoflurane until areflexic. This level of anesthesia was maintained throughout the surgical procedure. An incision was made inferior to the pinna, and 
the tympanic membrane was identified. Middle ear mesenchyme was aspirated, ossicles were removed, and the basal turn of the cochlea was visualized. Using a 30-gauge needle, the bony wall between the oval window and the round window was penetrated, and the contents were aspirated using a fine glass pipette. The modiolus was also destroyed. The skin incision was closed using cyanoacrylic glue. Animals were returned to their mothers and the rest of the litter within $2 \mathrm{~h}$. Temporal bones were examined by light microscopy after obtaining brain slices for electrophysiology experiments or after perfusion of animals in immunohistochemistry experiments to confirm the ablation. The procedures were approved by the University of Washington Animal Use Committee.

\section{Immunohistochemistry}

Mice that received unilateral cochlear ablations at P7 $(n=2)$ and P14 $(n=2)$ were overdosed with sodium pentobarbital and perfused transcardially with $4 \%$ paraformaldehyde at $1 \mathrm{wk}$ after surgery. After perfusion, the brains were removed and postfixed for an additional $2 \mathrm{~h}$ at room temperature (RT), then serially dehydrated in ethanol, cleared in methyl salicylate, and embedded in paraffin. A one-in-five series of $10-\mu \mathrm{m}$ coronal sections was mounted on slides. Sections were deparaffinized and rinsed in $0.01 \%$ Triton- $X$ in PBS (PBST) for $15 \mathrm{~min}$. Antigen retrieval was performed in $10 \mathrm{mM}$ citric acid ( $\mathrm{pH} \mathrm{6.0)} \mathrm{in} \mathrm{a}$ steamer for $25 \mathrm{~min}$ and then cooled for $10 \mathrm{~min}$ on ice. Slides were rinsed again in PBST for $15 \mathrm{~min}$ and then blocked for $1.5 \mathrm{~h}$ at RT in $10 \%$ normal serum, $0.1 \%$ Triton- $\mathrm{X}$, and $0.5 \%$ bovine serum albumin in PBS. Sections were next incubated overnight at $4^{\circ} \mathrm{C}$ with the primary antibodies: mouse anti-synaptic vesicle 2 (SV2, 1:100) and rabbit anti-microtubule associated protein 2 (MAP2, 1:500, Chemicon International, Temecula, CA). The SV2 antibody was generously provided by Dr. Sandra Bajjalieh and has been characterized previously (Buckley and Kelly 1985). The next day, tissue was rinsed for 30 min in PBST and incubated in Alexa Flour 488 conjugated goat anti-mouse and Alexa Flour 594 conjugated goat anti-rabbit (1:400, Molecular Probes) for $4 \mathrm{~h}$ at RT. Slides were then rinsed in PBS for $2 \mathrm{~h}$ and coverslipped with Glycergel mounting medium (Dako, Carpinteria, CA). Controls omitting the primary antibodies were included with every trial. Photomicrographs were taken using a CoolSnap HQ Digital Camera (Photometrics, Tucson, AZ) under a $\times 63$ objective on a Zeiss Axioplan 2 microscope. Images were captured using Slidebook 4.0 software (Intelligent Imaging Innovations, Santa Monica, CA). All photomicrograph figures were prepared using Photoshop 7.0 (Adobe Systems Incorporated, San Jose, CA).

\section{RE S U L T S}

\section{Electrophysiological identity of AVCN neurons}

There are two main neuronal cell types in the AVCN, bushy cells and stellate cells. They can be distinguished from each other by morphology or electrophysiology. Bushy cells have short bushy-like dendrites with round cell bodies innervated by large endbulb of Held auditory terminals. Stellate cells have long branched dendrites and receive bouton-like glutamatergic synapses from auditory terminals (reviewed in Young and Oertel 2004). In electrophysiological recordings, bushy cells fire only one or a few action potentials in response to prolonged depolarizing current injections, a hallmark of auditory neurons encoding timing information (reviewed in Oertel 1999; Trussell 1999). In contrast, stellate cells fire multiple action potentials in response to prolonged depolarizing current injections. Intracellular sharp electrode recordings have shown that the electrophysiological identity of AVCN neurons is established as early as age P7 (Wu and Oertel 1987). We confirmed this observation using whole cell recordings under currentclamp configuration and further characterized the firing properties of AVCN neurons so that determination of cell type can be made in the following experiments.

Data were collected from a total of $108 \mathrm{AVCN}$ neurons (38 cells were recorded by using AxoClamp 2B and 70 cells by AxoPatch 200B). Bushy cells and stellate cells were distinguished from each other by their firing patterns in response to prolonged current injection (Fig. 1). Both cell types possess a voltage sag in response to hyperpolarizing current injections, likely reflective of the presence of nonselective cation channels $\left(I_{\mathrm{h}}\right)$. Bushy cells fired single action potentials in response to threshold current (defined here as the minimum current needed to elicit action potentials; Fig. 1A). At more depolarizing current steps, a few action potentials (1-3) were elicited and followed by a steady state potential plateau (data not shown). Stellate cells fired multiple large action potentials distributed across the duration of the current injection (Fig. 1B). To investigate the profile of firing patterns, we plotted the number of action potentials against the amplitude of the injected currents relative to the neuron's threshold current for all individual neurons. Bushy cells showed an almost flat function (Fig. 1C, - -; note that several overlapped - - are present in each graph), whereas stellate cells showed an increase in number of action potentials with increasing current amplitude, and at more depolarizing current steps, some stellate cells showed fast adaptation, especially at P7 (Fig. 1C, $n=4,8$, and 6 bushy cells for P7, P14, and P21, respectively; $n=8,8$, and 4 stellate cells for P7, P14, and P21, respectively). Another apparent difference between the two cell types is neuronal excitability. Threshold currents for bushy cells were $0.55 \pm$ $0.17,0.48 \pm 0.16$, and $0.29 \pm 0.09 \mathrm{nA}$ for P7, P14, and P21, respectively. Threshold currents for stellate cells were $0.11 \pm$ $0.06,0.10 \pm 0.08$, and $0.11 \pm 0.10 \mathrm{nA}$ for P7, P14, and P21, respectively. At the same age, stellate cells were significantly more excitable than bushy cells (Fig. 1D). Furthermore, stellate cells possessed a stable excitability over the ages tested, whereas bushy cells appeared to become more excitable with age; threshold current at P21 is significantly smaller than at $\mathrm{P} 7 / \mathrm{P} 14$, and there is no significant difference between threshold currents between P7 and P14 (Fig. 1D).

\section{Development of mEPSCs in AVCN bushy cells}

Figure 2 shows development of mEPSCs of AVCN bushy cells in mice at ages P7, P14, and P21. mEPSCs were blocked by CNQX $(20 \mu \mathrm{M})$, a specific AMPA receptor (AMPAR) antagonist, indicating that mEPSCs are mediated by AMPARs (data not shown). The frequency of mEPSCs increased dramatically in bushy cells from P7 to P14/P21 (Fig. 2A). The examples were chosen to match the average frequency of mEPSCs in pooled data from each age group. Shown on the right (Fig. 2A) are three averaged traces from events of single cells normalized to their peaks. The examples were chosen to closely match the averaged $10-90 \%$ rise time and decay tau of pooled data. Figure $2, B-D$, shows the histogram distributions of mEPSC amplitude (bin width of $5 \mathrm{pA}$ ), 10-90\% rise time (bin width of $20 \mu \mathrm{s}$ ), and decay tau (bin width of $100 \mu \mathrm{s}$ ) of all mEPSCs from all cells $(n=6,6,9$ cells for P7, P14, and P21, respectively). These histograms show the ranges and distributions of mEPSC parameters across the ages tested. mEPSCs at 


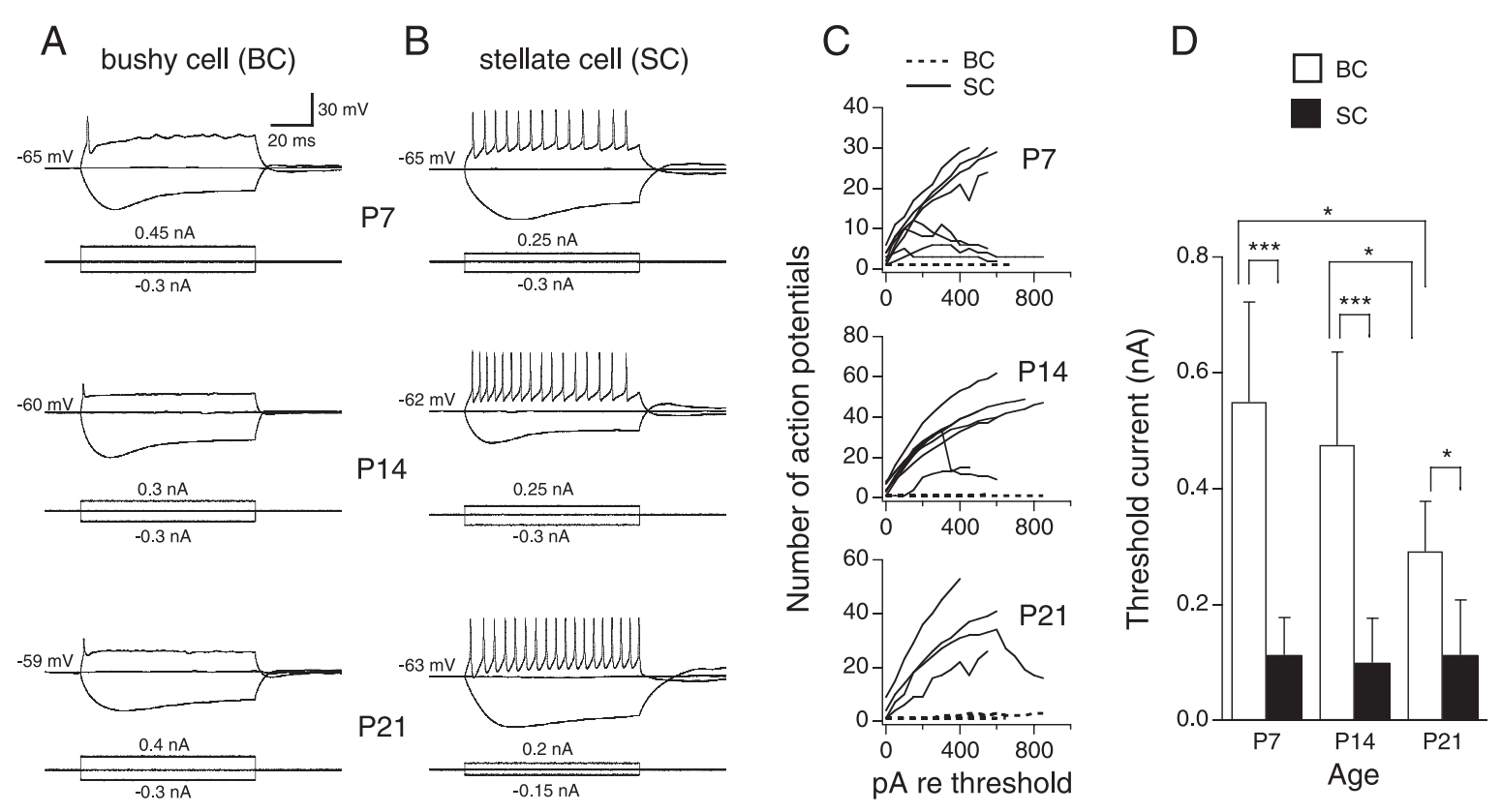

FIG. 1. Electrophysiological identity of mouse anteroventral cochlear nucleus (AVCN) neurons at ages postnatal day 7 (P7), P14, and P21. A: bushy cells fire single action potentials in response to prolonged $(100 \mathrm{~ms})$ depolarizing current injection. $B$ : stellate cells fire multiple action potentials distributed across the duration of the current injection. $C$ : number of action potentials was plotted against the amplitude of the injection currents relative to the threshold current (the minimum step current amplitude that is required to elicit action potentials) for individual neurons. Bushy cells show an almost flat function $(---, n=4,8$, and 6 cells for P7, P14, and P21, respectively), whereas stellate cells show an increase in number of action potentials with increasing current amplitude $(n=8,8$, and 4 cells for P7, P14, and P21, respectively). Some stellate cells show adaptation, i.e., a decrease in number of spikes in response to more depolarizing current steps. $D$ : bushy cells are less excitable than stellate cells, as evidenced by their significantly larger threshold currents ( $\square$ and $\square$ for bushy and stellate cells, respectively). Whereas stellate cells lack developmental changes in excitability from P7 to P14 to P21, bushy cells become more excitable at P21 than P7/P14. Means $\pm \mathrm{SD}$ are shown. $* P<0.05, * * * P<0.001$ (unpaired $t$-test).

P7 appeared to have broader distributions in 10-90\% rise time and decay tau than those at P14/P21. Due to the large variation in mEPSC frequency in different cells, the distributions are possibly biased toward the cells with the largest number of events. Ideally, equal numbers of events from each cell should be pooled to make the histograms. However, in some cells, only a few events can be recorded, even in a prolonged period of recording, so we decided to plot all events in these histograms and then present another group of data to show the means and SDs of each parameter (Fig. 2, $E-H$ ).

We observed significant changes in the frequency and kinetics but not the amplitude of mEPSCs across the ages tested (Fig. 2, $E-H$ ). Frequency of mEPSCs increased significantly from $\mathrm{P} 7$ to P14 or P21 (Fig. 2E, ANOVA post hoc Fisher's test $P<0.05$ and 0.01 , respectively). No significant difference was detected in mEPSC frequency between P14 and P21. mEPSCs of bushy cells recorded from P21 mice show a significantly shorter $10-90 \%$ rise time than those from P7 animals. The difference in 10-90\% rise time between P7 and P14 is not significant, although the trend was suggestive $(P=0.086)$. Decay tau of mEPSCs gets smaller over age. A significant difference was detected by ANOVA $(P<0.05)$, and post hoc Fisher's tests show that decay tau at P14 or P21 is significantly smaller than at P7, and no significant difference was detected between P14 and P21. Numeric data are shown in Table 1.

To determine whether dendritic filtering exists in bushy cells at ages tested, we plotted mEPSC $10-90 \%$ rise time against decay tau in bushy cells for the three age groups (Fig. 2,I-K). Due to the cable properties of dendrites, synaptic inputs recorded at the soma are expected to be attenuated in amplitude (Rall 1967; Rall et al. 1967). The time course of synaptic events also changes as a function of input location; the further from the soma a synaptic event occurs, the slower its time course is (Rall et al. 1967; Rinzel and Rall 1974). Therefore if dendritic filtering exists, one would expect that the synaptic events (in our case mEPSCs) with long rise time would also have long decay time. Thus a positive correlation is indicative of dendritic filtering (Gardner et al. 1999). No correlations between mEPSC $10-90 \%$ rise time and decay tau were found; linear regression analysis gave rise to correlation coefficients close to zero $(R=-0.02,0.09$, and 0.05 for $\mathrm{P} 7, \mathrm{P} 14$, and $\mathrm{P} 21$, respectively). This indicates a lack of dendritic filtering in AVCN bushy cells at the ages tested, consistent with the fact that excitatory inputs from the auditory nerve impinge onto the somata and not the dendrites of bushy cells (Cant and Morest 1979; Lenn and Reese 1966).

\section{Development of mEPSCs in AVCN stellate cells}

Figure 3 shows the development of mEPSCs in AVCN stellate cells $(n=10,7,5$ cells for P7, P14, and P21, respectively). Recordings of mEPSCs of AVCN stellate cells from mice age P7, P14, and P21 show mEPSCs of similar number and amplitude (Fig. 3A, left). Similar mEPSC kinetics were also seen across ages, as shown by the three averaged traces from events of single cells, normalized to their peaks (Fig. 3A, right). The 10-90\% rise time and decay tau at $\mathrm{P} 7$ appeared to have a broader range than at P14 or P21. However, no significant differences were detected in averaged mEPSC frequency, amplitude, 10-90\% rise time, or decay tau among different age groups (Fig. 3, $E-H$; Table 1; ANOVA $P>$ 0.05). As stated previously, all mEPSC events from all cells in 
A

P7

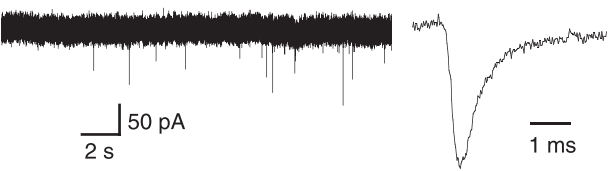

P14

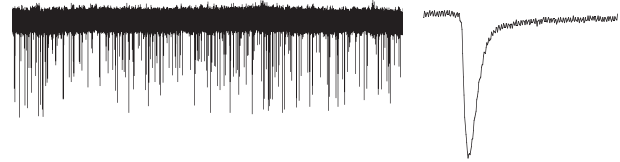

P21
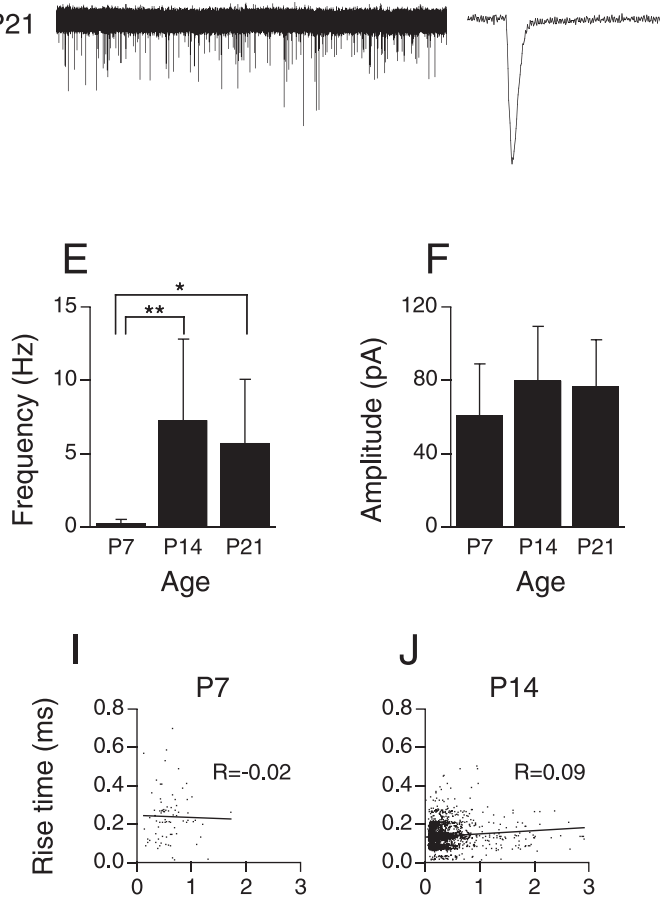

B
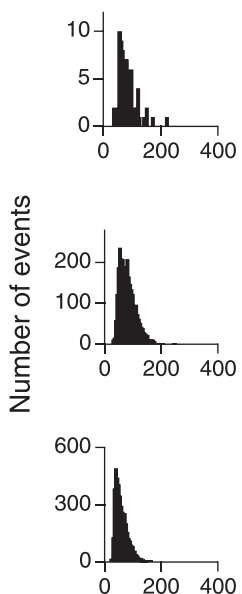

Amplitude (pA)

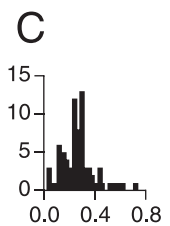

$\mathrm{D}$
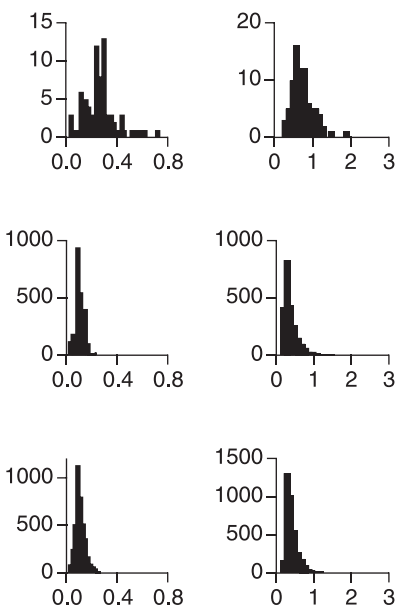

Rise time (ms) Decay tau (ms)

FIG. 2. Development of spontaneous miniature excitatory postsynaptic currents (mEPSCs) in AVCN bushy cells. A, left: 3 original chart recordings of mEPSCs of AVCN bushy cells from mice ages P7, P14, and P21. Cells were voltage clamped at $-60 \mathrm{mV}$. Strychnine $(1 \mu \mathrm{M})$ and gabazine $(10 \mu \mathrm{M})$ were present in the perfusion solution to block glycine and GABA receptors. Right: averaged traces from mEPSCs of 3 individual cells, normalized to their peaks. $B-D$ : histogram distributions of mEPSC amplitude (bin width of $5 \mathrm{pA}$ ), 10-90\% rise time (bin width of $20 \mu \mathrm{s}$ ), and decay time constant (decay tau, bin width of 100 $\mu$ s) of all events of all cells ( $n=6,6,9$ cells for P7, P14, and P21, respectively) at the 3 different ages. Labels indicating age at the far left in $A$ apply to histograms in $B-D$. E: frequency of mEPSCs increases significantly from P7 to P14 or P21. No significant difference was detected in mEPSC frequency between P14 and P21. F: amplitude of mEPSCs shows no difference across ages tested. $G$ : mEPSCs of bushy cells recorded from P21 mice rise significantly faster than those of P7 mice as evidenced by briefer $10-90 \%$ rise time of mEPSCs. The difference between P7 and P14 is not significant $(P=0.086)$. $H$ : decay tau of mEPSCs gets progressively smaller from P7 to P21. Significant differences were detected by ANOVA $(P<0.05)$, and post hoc Fisher's tests show that decay tau at P14 is significantly smaller than that at P7, and decay tau at P21 is also significantly smaller than that at P7, but no significant difference was detected between P14 and P21. Note that to generate graphs $F-H$, an averaged trace was obtained for each cell by averaging all detected events in that single cell. Amplitude, $10-90 \%$ rise time, and decay tau of the averaged mEPSCs were measured, then data were pooled in each age group. Means \pm SD are shown in $E-H$. $* P<0.05$, $* * P<$ 0.01 (ANOVA post hoc Fisher's test). I-K: plots of 10-90\% rise time against decay tau of mEPSCs in AVCN bushy cells at ages P7, P14, and P21. No correlations between mEPSC 10-90\% rise time and decay tau were found in AVCN bushy cells at the ages tested, indicating a lack of dendritic filtering, consistent with the fact that excitatory inputs from the auditory nerve impinge onto the soma, not the dendrites, of bushy cells.

each age group were plotted in the distribution histograms. Because the number of events in individual cells varies widely, the distributions are biased toward the cells with the largest number of events. In contrast, to generate the pooled data, we obtained a trace by averaging all events in each cell. We then measured the parameters (amplitude, rise time, and decay tau) of the averaged trace, and considered each measurement as one data point. We presented the means $\pm \mathrm{SD}$ of the values obtained from the averaged traces (equal to the number of cells) in each age group. Therefore one should not estimate the means and SDs based on the distribution histograms. Relatively strong positive correlations between $10-90 \%$ rise time and decay tau are seen in stellate cells at all ages tested (Fig. 3, $I-K ; R=0.32,0.24$, and 0.28 for $\mathrm{P} 7, \mathrm{P} 14$, and $\mathrm{P} 21$, respectively), suggestive of dendritic filtering. These data are consistent with the fact that excitatory inputs from the auditory nerve contact dendrites of stellate cells (Cant 1981; Smith and Rhode 1989). 
TABLE 1. Comparisons of mEPSC properties in bushy and stellate cells at different ages

\begin{tabular}{|c|c|c|c|c|}
\hline & P7 & P14 & $\mathrm{P} 21$ & ANOVA $P$ Value \\
\hline Bushy cell, $(N)$ & 6 & 6 & 9 & \\
\hline Frequency $(\mathrm{Hz})$ & $0.2 \pm 0.3$ & $7.3 \pm 5.5^{* *}$ & $5.7 \pm 4.4^{*}$ & $0.0190 *$ \\
\hline Amplitude (pA) & $-61 \pm 28$ & $-80 \pm 30$ & $-77 \pm 25$ & 0.4293 \\
\hline $10-90 \%$ rise time $(\mathrm{ms})$ & $0.18 \pm 0.08$ & $0.13 \pm 0.01$ & $0.12 \pm 0.01 *$ & 0.0684 \\
\hline Decay tau (ms) & $0.47 \pm 0.12$ & $0.26 \pm 0.13 * *$ & $0.19 \pm 0.05^{* *}$ & $0.0002 * *$ \\
\hline Stellate cell $(N)$ & 10 & 7 & 5 & \\
\hline Frequency $(\mathrm{Hz})$ & $0.8 \pm 1.3$ & $1.7 \pm 2.6$ & $1.7 \pm 2.0$ & 0.5864 \\
\hline Amplitude (pA) & $-58 \pm 16(\mathrm{n}=9)$ & $-52 \pm 18$ & $-53 \pm 17$ & 0.7868 \\
\hline $10-90 \%$ rise time $(\mathrm{ms})$ & $0.18 \pm 0.07(\mathrm{n}=9)$ & $0.18 \pm 0.05$ & $0.20 \pm 0.10$ & 0.8473 \\
\hline Decay tau (ms) & $0.48 \pm 0.34(\mathrm{n}=9)$ & $0.46 \pm 0.22$ & $0.53 \pm 0.37$ & 0.9127 \\
\hline
\end{tabular}

Means \pm SD are shown. $n$ : number of cells; $* P<0.05$. ** $P<0.01$, ANOVA, and post hoc Fisher's tests (between P14 and P7 or P21 and P7); no significant difference was detected in any of the parameters between P14 and P21 in both cell types at any age.
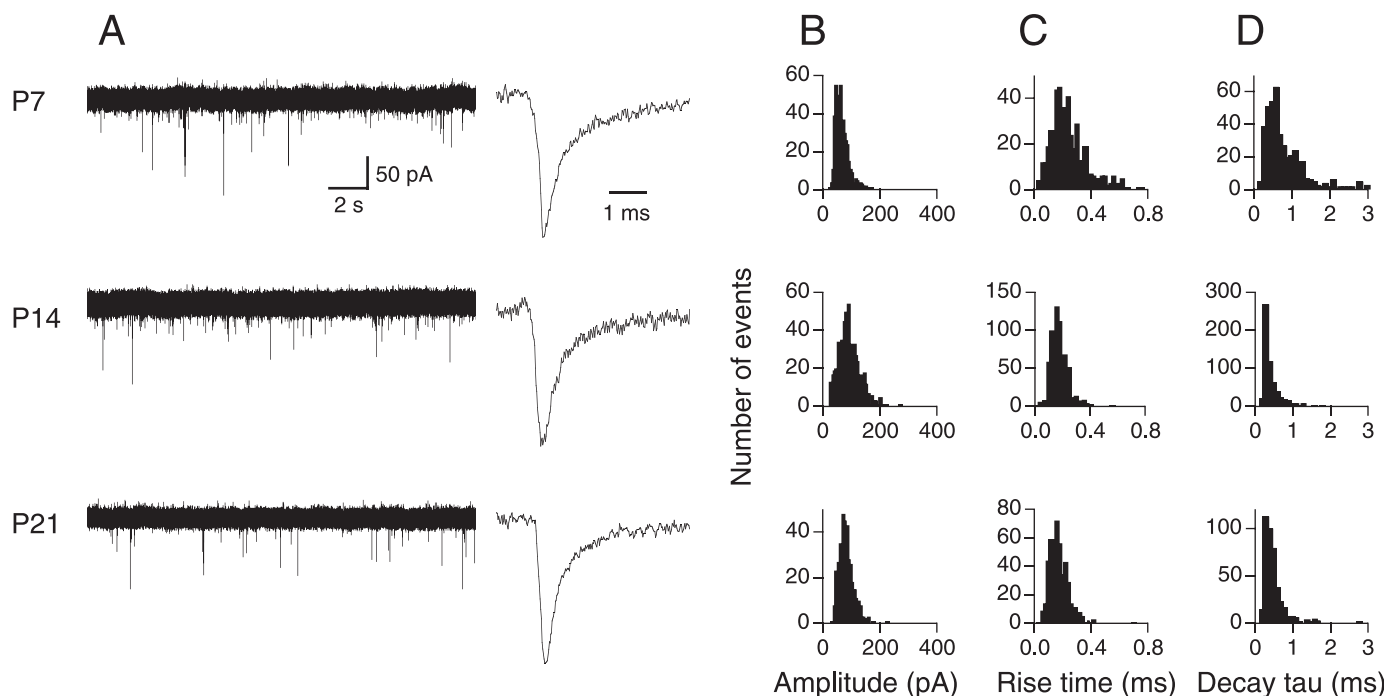

Amplitude (pA) Rise time (ms) Decay tau (ms)
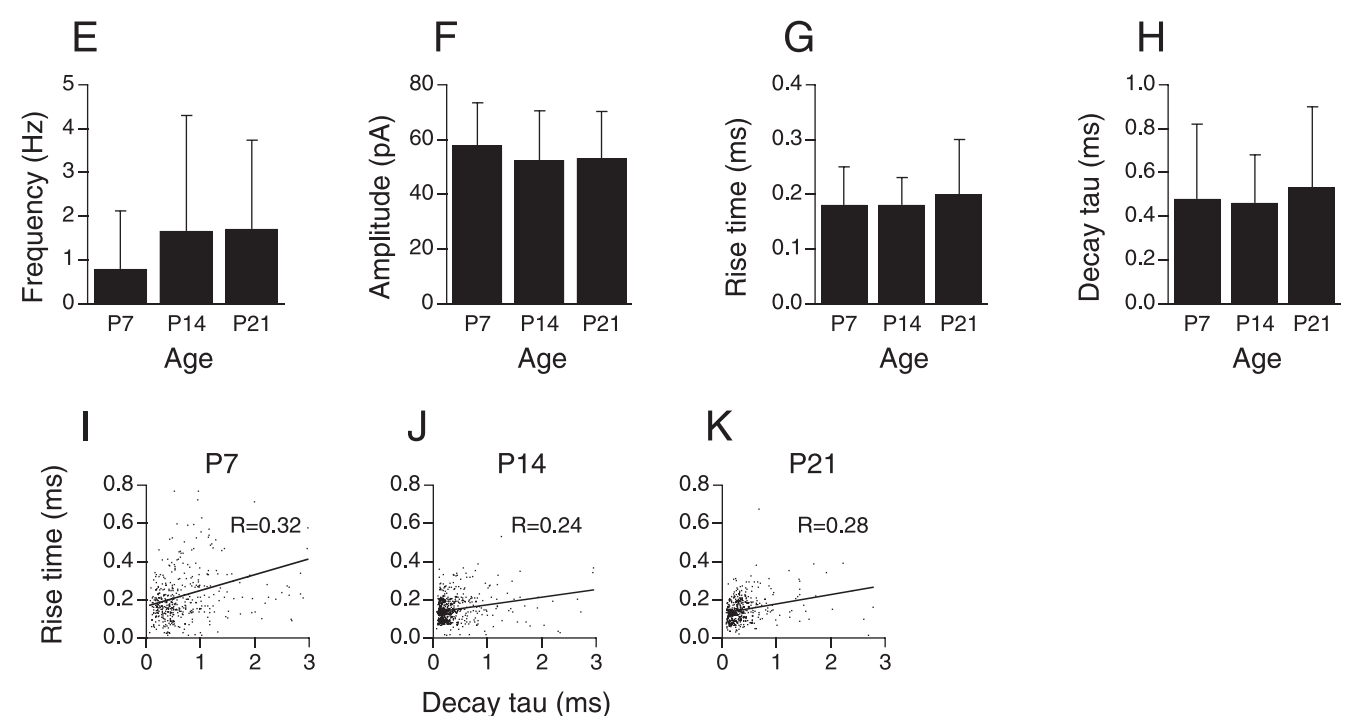

FIG. 3. Development of mEPSCs in AVCN stellate cells $(n=10,7,5$ cells for P7, P14, and P21, respectively). A-D: for figure legends, see Fig. 2. $E-H$ : no significant differences are detected in mEPSC frequency, amplitude, $10-90 \%$ rise time, or decay tau among different age groups (ANOVA $P>0.05$ ). $I-K$ : plots of $10-90 \%$ rise time against decay tau of mEPSCs in AVCN stellate cells at ages P7, P14, and P21. Positive correlations between mEPSC 10-90\% rise time and decay tau are seen in stellate cells at the ages tested. This is suggestive of dendritic filtering in these neurons, consistent with the fact that excitatory inputs from the auditory nerve impinge onto their dendrites. 
Effects of cochlea ablation performed at P7 on development of $\mathrm{MEPSC}$ (recorded at P14)

We performed cochlea ablations at P7 and examined mEPSCs at P14, when AVCN bushy cell death had reached its maximum (Mostafapour et al. 2000). Physiological identity of the two main neuron types is preserved after cochlea ablation (data not shown), consistent with previous reports on rats (Francis and Manis 2000). Figure 4 shows mEPSC recordings obtained from surviving bushy cells $(n=7$ cells). Figure $4 A$ shows examples of an original chart recording of mEPSCs and an averaged trace (normalized to the peak of the trace for P14 bushy cells in Fig. 2). CNQX (20 $\mu \mathrm{M})$ completely blocked
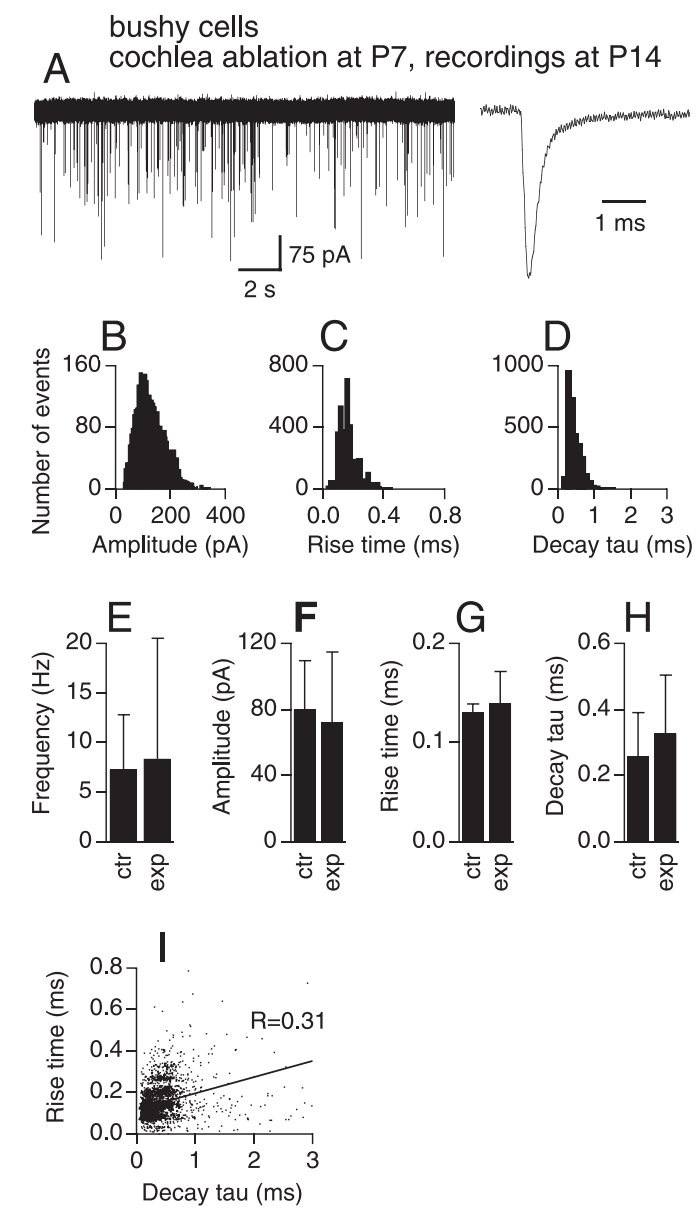

FIG. 4. Effects of cochlea ablation performed during the critical period on mEPSCs of AVCN bushy cells. The frequency and kinetics of mEPSCs in AVCN bushy cells 7 days after unilateral cochlea ablation (surgery performed at P7) are similar to those recorded from normal mice of the same age (P14). $A$ : original chart recording of mEPSCs of a bushy cell representative of mEPSC frequency of the group, and an averaged trace of all events detected from another cell representative of mEPSC kinetics of the group. The averaged trace was normalized to its peak with the averaged traces in Fig. $2 A$. $B-D$ : histogram distributions of mEPSC amplitude (bin width of $5 \mathrm{pA}$ ), 10-90\% rise time (bin width of $20 \mu \mathrm{s}$ ), and decay tau (bin width of $100 \mu \mathrm{s}$ ) of all events from 7 bushy cells obtained from the AVCN ipsilateral to the cochlea ablation. $E-H$ : unpaired $t$-test detected no difference in average frequency, amplitude, $10-90 \%$ rise time, and decay tau of mEPSCs between control (same data for P14 in Fig. 2, $E-H)$ and the experimental group $(P>0.05)$. Means \pm SD are shown. Ctr, control; exp, experimental group. I. Seven days after unilateral cochlea ablation (surgery performed at P7), a positive correlation between mEPSC $10-90 \%$ rise time and decay tau is seen in bushy cells in the AVCN ipsilateral to the cochlea ablation, suggestive of emergence of dendritic filtering in bushy neurons that survived the surgery.
mEPSCs in surviving bushy cells, indicative of unaltered pharmacology of mEPSCs (data not shown). Histogram distributions of mEPSC amplitude (bin width of $5 \mathrm{pA}$ ), 10-90\% rise time (bin width of $20 \mu \mathrm{s}$ ), and decay tau (bin width of $100 \mu \mathrm{s}$ ) show similar patterns to the bushy cells of the same age (P14) in Fig. 2. A slightly broader range of mEPSC amplitude is seen for activity-deprived bushy cells (Fig. 4B). Unpaired $t$-test detected no difference in mEPSC frequency, amplitude, 10$90 \%$ rise time, and decay tau between control cells at P14 (same data as in Fig. 2, $E-H$ ) and activity-deprived cells at the same age (Fig. 4, $E-H$ ). mEPSCs of the experimental group appeared to have larger variability (SD bars) in frequency, amplitude, 10-90\% rise time, and decay tau.

A major difference between mEPSCs recorded from activitydeprived bushy cells and normal cells is the relationship between rising time and decay tau. A fairly strong positive correlation (Fig. $4 I, R=0.31$ ) between mEPSC $10-90 \%$ rise time and decay tau is seen in activity-deprived bushy cells as compared with normal P14 bushy cells (Fig. $2 J, R=0.09 ; z$ test, $P<0.001)$. This observation suggests dendritic filtering in surviving bushy cells, probably resulting from added synaptic inputs on their dendrites. To further examine effects of cochlea ablation on the expression patterns of synaptic contacts, we examined the distribution pattern of synaptic vesicle protein 2 (SV2), a transmembrane protein that is commonly present at synaptic vesicles (Buckley and Kelly 1985). The tissue was double labeled with microtubule-associated protein 2 (MAP2), one of the most abundant proteins in neurons that is highly expressed in dendrites. Unilateral cochlea ablation was performed at P7 and animals were allowed to survive for 7 days. The contralateral side of each slice was used as a within-slice control. We observed a ring of SV2 labeling around the somata in the contralateral bushy cells (Fig. 5A) that was mostly absent on the ipsilateral side (Fig. 5B). However, the overall density of SV2 labeling in the neuropil appeared qualitatively similar between sides.

In contrast to bushy cells, cochlea ablation resulted in no significant changes in mEPSCs of stellate cells (Fig. 6, $n=9$ cells). Figure $6 A$ shows examples of an original chart recording of mEPSCs and an averaged trace (normalized to the peak of the trace for P14 stellate cells in Fig. 3). Histogram distributions of mEPSC amplitude, 10-90\% rise time, and decay tau show similar patterns to the control cells of the same age (P14) in Fig. 3 (Fig. 6, $B-D$ ). Unpaired $t$-test detected no difference in mEPSC frequency, amplitude, $10-90 \%$ rise time, and decay tau between control cells at P14 (same data as in Fig. 3, $E-H$ ) and activity-deprived cells at the same age (Fig. $6, E-H, P>$ 0.05). mEPSCs of the experimental group appeared to have larger variability (SD bars) in frequency, amplitude, 10-90\% rise time, and decay tau. Furthermore, the correlation coefficient $(R=0.30)$ between mEPSC $10-90 \%$ rise time and decay tau is comparable to that of stellate cells at P14 in normal animals (Fig. 6I; $z$ test, $P>0.05$ ).

\section{Effects of cochlea ablation performed at P14 on development of mEPSCs (recorded at P21)}

Synaptic inputs may be less susceptible to activity modulation after the critical period. To test this hypothesis, we examined the development of mEPSCs if cochlea ablation is performed after the critical period, we performed cochlea 

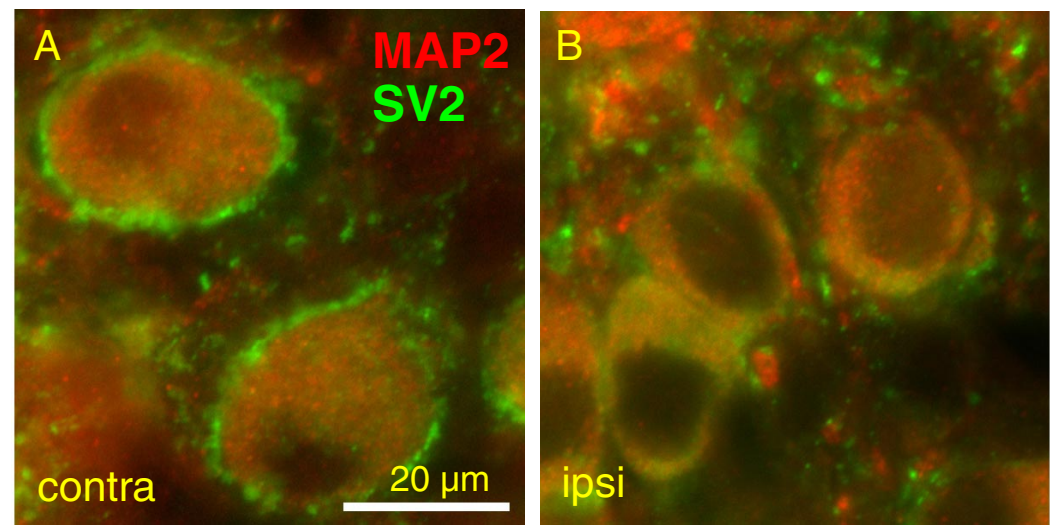

FIG. 5. Effects of cochlea ablation performed during the critical period on synaptic vesicle 2 (SV2) expression in AVCN bushy cells. A: representative section showing bushy cells labeled for SV2 (green) and MAP2 (red) in the AVCN contralateral (contra) to the cochlea ablation. $B$ : representative section showing bushy cells in the AVCN ipsilateral (ipsi) to the cochlea ablation. Note the presence of the ring of SV2 labeling around the somata in the contralateral bushy cells that is mostly absent on the ipsilateral side. However, the overall density of SV2 labeling in the neuropil qualitatively appeared similar between sides. Scale bar, $20 \mu \mathrm{m}$. ablation at P14, and recorded mEPSCs in AVCN neurons at $\mathrm{P} 21$. We observed similar patterns in histogram distribution of mEPSC amplitude, 10-90\% rise time, and decay tau in activity-deprived bushy cells to those of control cells at the same age (P21; Fig. 7). Unpaired $t$-test detected no difference in

stellate cells

A cochlea ablation at $\mathrm{P} 7$, recordings at $\mathrm{P} 14$
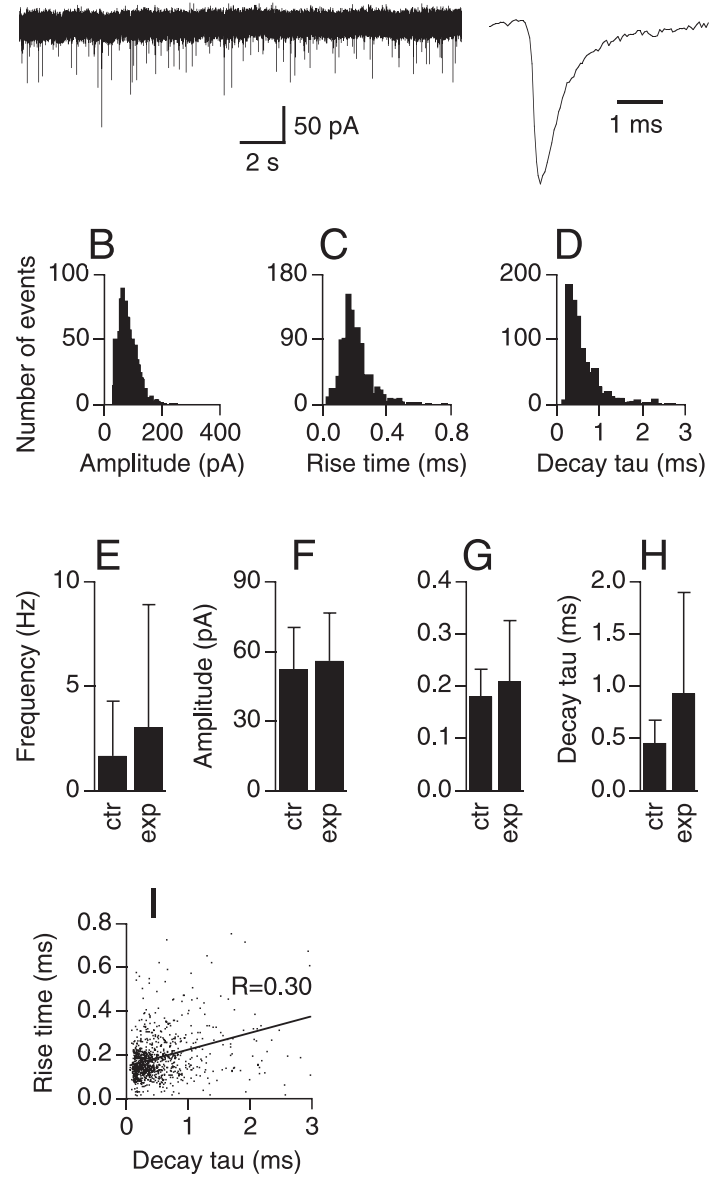

FIG. 6. Effects of cochlea ablation performed during the critical period on $\mathrm{mEP}$ $\mathrm{SCs}$ of AVCN stellate cells. The frequency and kinetics of mEPSCs in AVCN stellate cells 7 days after unilateral cochlea ablation (surgery performed at P7) are similar to those recorded from normal mice of the same age (P14). $A-H$ : for figure legends, see Fig. 4. Note that the averaged trace was normalized to its peak with the averaged traces in Fig. 3A. Experimental data were pooled from 9 stellate cells obtained from the AVCN ipsilateral to the cochlea ablation. I: 7 days after unilateral cochlea ablation (surgery performed at P7), the correlation between $\mathrm{mEPSC} 10-90 \%$ rise time and decay tau remains unchanged in AVCN stellate cells.
mEPSC frequency, amplitude, 10-90\% rise time, and decay tau between control cells at P21 (same data as in Fig. 2, $E-H$ ) and activity-deprived cells at the same age (Fig. 7, E-H). A stronger positive correlation $(R=0.14)$ between mEPSC $10-90 \%$ rise time and decay tau is seen in activity-deprived

\section{A cochlea ablation at $\mathrm{P} 14$, recordings at $\mathrm{P} 21$}
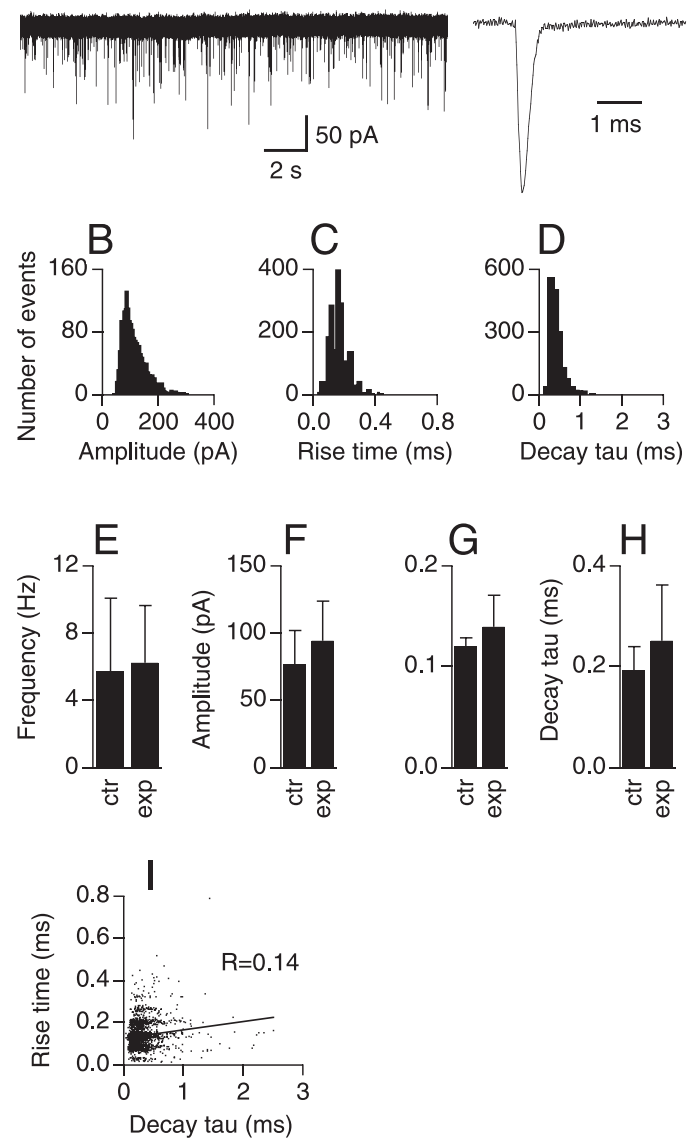

FIG. 7. Effects of cochlea ablation performed after the critical period on mEPSCs of AVCN bushy cells. The frequency and kinetics of mEPSCs in AVCN bushy cells 7 days after unilateral cochlea ablation (surgery performed at P14) are similar to those recorded from normal mice of the same age (P21). $A-H$ : for figure legends, see Fig. 4 . Note that the averaged trace was normalized to its peak with the averaged traces in Fig. $2 A$. Experimental data were pooled from 5 bushy cells obtained from the AVCN ipsilateral to the cochlea ablation. I: 7 days after unilateral cochlea ablation (surgery performed at P14), a stronger positive correlation between mEPSC $10-90 \%$ rise time and decay tau is seen in AVCN bushy cells than control. 

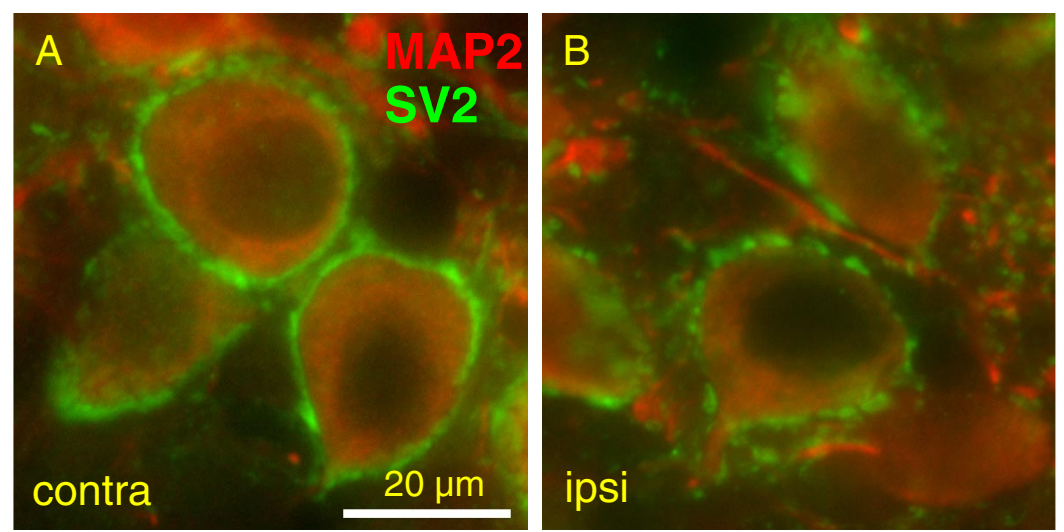

FIG. 8. Effects of cochlea ablation performed after the critical period on SV2 expression in AVCN bushy cells. Representative sections showing SV2 (green) and MAP2 (red) labeling of bushy cells contralateral (contra, $A$ ) and ipsilateral (ipsi, $B$ ) to the cochlea ablation. Note the presence of the ring of SV2 labeling around the somata in both panels. However, the SV2 label on the ipsilateral somas appears less continuous than on the contralateral side. Scale bar, $20 \mu \mathrm{m}$. bushy cells than control $(R=0.05$; Fig. $7 I$; $z$ test $P<0.01)$. A ring of SV2 labeling around the somata of bushy cells was seen in both the contralateral and the ipsilateral AVCN, but the SV2 labeling on the ipsilateral somas appeared less continuous than on the contralateral side (Fig. 8).

Similarly, cochlea ablation resulted in no changes in frequency, amplitude, and time courses of mEPSCs of stellate cells (Fig. 9, $n=6$ cells). The histograms (Fig. 9, $B-D$ ) show similar patterns to those of the stellate cells of the same age (P21) in normal animals (Fig. 3). Unpaired $t$-test detected no difference in mEPSC frequency, amplitude, 10-90\% rise time, and decay tau between control cells at P21 (same data as in Fig. $3, E-H)$ and activity-deprived cells at the same age (Fig. 9, $E-H)$. A significant increase in correlation coefficient $(R=$ 0.41 , compared with $R=0.28$ for P21 stellate cells under control conditions) between mEPSC $10-90 \%$ rise time and decay tau was seen (Fig. 9I; $z$ test, $P<0.01$ ). MAP2 and SV2 staining in stellate cells is not shown due to difficulties in identifying stellate cells in the stained slices.

\section{I S C U S S I O N}

We investigated the development of spontaneous miniature excitatory synaptic currents (mEPSCs) in AVCN neurons in mice at ages P7, P14, and P21. We showed that the frequency of mEPSCs in bushy cells increases significantly with little changes in amplitude and that mEPSCs become progressively briefer. In contrast, stellate cells lack significant changes in mEPSCs during these ages. We also examined the effects of unilateral cochlea ablation on development of mEPSCs. Cochlea ablation performed at P7 and P14 did not alter mEPSC frequency, amplitude or kinetics but did lead to the emergence of dendritic filtering in bushy cells. Stellate cells also show no changes in mEPSCs compared with age-matched controls except for an increase in dendritic filtering when the surgery was performed at $\mathrm{P} 14$.

\section{Development of mEPSCs in AVCN neurons and correlation to their morphology}

Synapses at AVCN neurons are present at birth. During the first weeks in postnatal development, auditory nerve endings impinging onto bushy cells in mouse AVCN show substantial changes in morphology (Limb and Ryugo 2000). At P7, auditory nerve inputs to AVCN bushy cells are bouton like and lack any branches at the terminals. At P14, the nerve endings increase substantially in size (10- to 15-fold larger than P7).
Most nerve endings are cup-shaped at this age, but some of them have branches at the terminals and can be identified as nascent endbulbs. Assuming that an increase in size of nerve endings is associated with an increase in number of synapses and thus more release sites, the dramatic change in nerve

\section{A cochlea ablation at $\mathrm{P} 14$, recordings at $\mathrm{P} 21$}
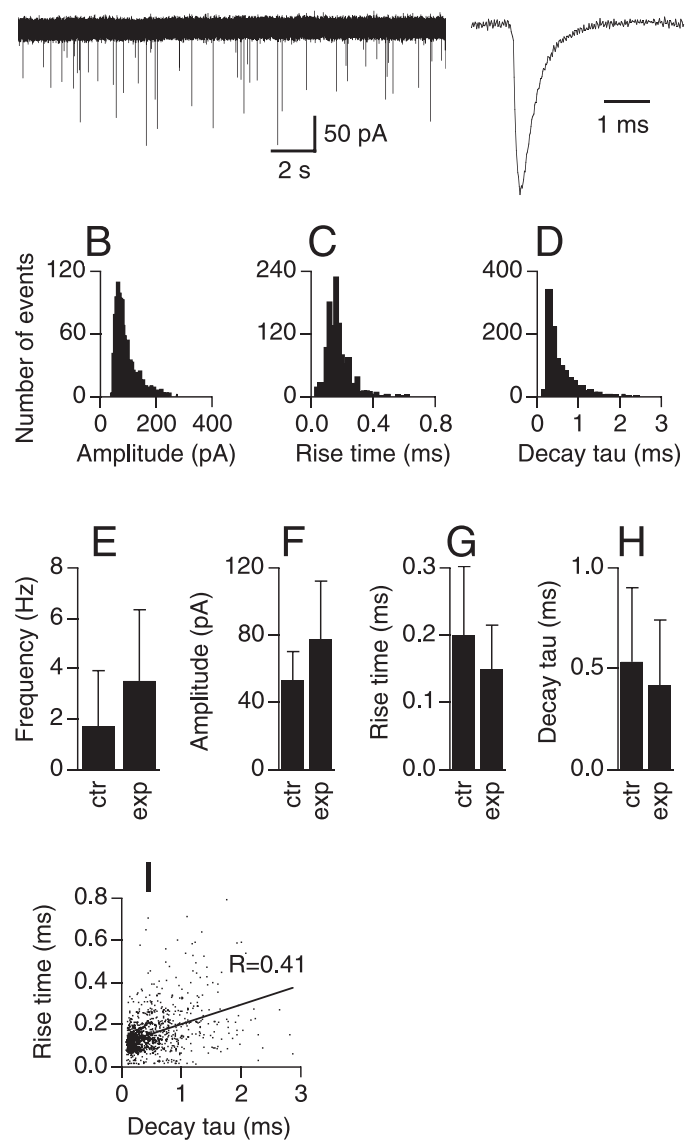

FIG. 9. Effects of cochlea ablation performed after the critical period on mEPSCs of AVCN stellate cells. The frequency and kinetics of mEPSCs in AVCN stellate cells 7 days after unilateral cochlea ablation (surgery performed at P14) are similar to those recorded from normal mice of the same age (P21). $A-H$ : for figure legends, see Fig. 4 . Note that the averaged trace was normalized to its peak with the averaged traces in Fig. 4A. Experimental data were pooled from 6 stellate cells obtained from the AVCN ipsilateral to the cochlea ablation. I: 7 days after unilateral cochlea ablation (surgery performed at P14), the correlation between mEPSC $10-90 \%$ rise time and decay tau is increased in AVCN stellate cells. 
ending size could well account for the sharp increase identified here in mEPSC frequency in bushy cells from P7 to P14 (35-fold) because the frequency of spontaneous EPSCs seems to be correlated with the number of auditory inputs (Gardner et al. 1999). Four weeks after birth (P28), the auditory nerve endings on AVCN bushy cells form several branches that are similar in caliber to their parent branch and can be clearly identified as nascent endbulbs. However, the overall coverage of the cell bodies by the nerve terminals appears similar to that of P14 mice (Limb and Ryugo 2000). This may explain why we observed that the frequency of mEPSCs in bushy cells does not further increase from P14 to P21. The increased mEPSC frequency, especially from P7 to P14, indicates the maturation of some presynaptic elements such as number of synapses, activity level of individual release sites or a combination of both. Future anatomical measures are needed to further determine which is the case.

Along with morphological maturation of presynaptic terminals and postsynaptic neurons (Limb and Ryugo 2000), AMPAR-mediated mEPSCs at the endbulb of Held synapses in mouse AVCN bushy cells become significantly faster in their time courses across the critical period (Fig. 2). This is consistent with previous reports on development of endbulb of Held synaptic physiology in the cochlear nucleus in rats (Bellingham et al. 1998) or chickens (Brenowitz and Trussell 2001). The faster time course of mEPSCs parallels, and may account in part for, the development of faster evoked EPSCs (eEPSCs) in rat AVCN bushy cells (Bellingham et al. 1998) or chicken nucleus magnocellularis neurons (Brenowitz and Trussell 2001). The decay time constants in P21 bushy cells are half as large those reported in the Gardener et al. study (1999). This discrepancy may be due to the following reasons. The mouse strain is different; we used C57BL/6, whereas Gardener et al. (1999) used CBA and ICR. The recording temperature we used $\left(34-36^{\circ} \mathrm{C}\right)$ is slightly higher than the temperature they used $\left(34^{\circ} \mathrm{C}\right)$. Synaptic events are expected to have faster time course at a higher temperature within the physiological range. The age of animals may be a factor, too. We used P21 mice, and Gardener et al. (1999) used mice age between P18 and 25. The age difference may also account for the observation that the SD of the decay tau we obtained $(0.05 \mathrm{~ms})$ is much smaller than that Gardener et al. (1999) obtained (0.15 ms). Interestingly, in aging DBA mice, mIPSCs in AVCN bushy cells showed reduced frequency and a slower time course compared with young animals (Wang and Manis 2005), precisely the opposite to what was observed in developing animals.

Research on the morphological development of auditory nerve endings impinging on AVCN stellate cells at the ages we studied is lacking. Based on our electrophysiological observations, auditory nerve endings onto stellate cells are not expected to show substantial morphological changes from the first to the third week after birth. This may indicate that maturation of the excitatory inputs to stellate cells occurs either prior to P7 or after the third postnatal week. Morphological studies are needed to test these alternative hypotheses.

\section{mEPSCs in surviving bushy cells after cochlea ablation}

Cochlea ablation results in degeneration of the auditory nerve terminals, but the overall strength of synaptic inputs onto surviving cochlear nucleus neurons seems to be preserved, likely due to reinnervation of cochlear nucleus neurons by fibers from sources other than the ipsilateral auditory nerve. In rats, when the auditory nerve is transected, auditory nerve terminals start degenerating within $24 \mathrm{~h}$ after the surgery, and by $5-9$ days, most degenerating terminals disappear. What is interesting is that electron microscopy confirms reinnervation of AVCN neurons during this time probably due to reoccupation of nearby intact terminals containing transmitter vesicles (Gentschev and Sotelo 1973) or an increase in axonal sprouting from medial olivocochlear neurons (Illing et al. 2005). In cats, cochlea ablation results in degeneration of endbulbs of Held, the auditory nerve endings on AVCN bushy cells, but leaves other types of synapses intact (Cant and Morest 1979). In addition, hearing deprivation in mice leads to a significant increase in nonauditory nerve endings impinging on AVCN neurons and a decrease in auditory nerve endings, but the overall cell membrane covered by the auditory plus the nonauditory nerve endings is unchanged (Trune and Morgan 1988). Although these structural changes have been known for some time, physiological studies are lacking to determine if there are functional changes in synaptic transmission after manipulations of the auditory afferent inputs.

Assuming a similar time course of degeneration of the auditory nerve terminals after cochlea destruction among the rat, cat, and the mouse, presumably most or all auditory terminals at the synapses in the AVCN would disappear in $\sim 1$ week. This would lead one to predict much weaker spontaneous synaptic activity in activity-deprived neurons compared with neurons in normal hearing animals of the same age. However, one may not observe a significant difference in spontaneous synaptic activity in activity-deprived neurons if there is a compensatory reaction via reinnervation or regeneration of synapses from other sources including the AVCN neuron itself (auto-synapses). If reinnervation and/or regeneration of inputs occur, one prediction is that mEPSCs of similar properties to normal neurons should be recorded in the surviving neurons 1 or 2 wk after cochlea ablation at which time maximal cell death $(30-70 \%$ of the total) in AVCN has occurred (Mostafapour et al. 2000).

Our results support the occurrence of reinnervation and/or regeneration. Seven days after cochlea ablation performed either at P7 or P14, mEPSCs in AVCN bushy cells are maintained at a similar level in terms of frequency, amplitude, and time course to that of AVCN neurons of normal animals of the same age. Seven days after cochlea ablation performed at $\mathrm{P} 7$, a positive correlation between mEPSC $10-90 \%$ rise time and decay tau was detected, indicative of synaptic inputs onto dendrites and emergence of dendritic filtering in surviving bushy neurons. A positive correlation was also seen when the surgery was performed at P14, suggesting that at least some events occurred at locations other than the soma. Assuming that the frequency of mEPSCs at single synapses is not changed by cochlea ablation, we speculate the new synapses formed and impinged on dendrites of surviving bushy cells. These physiological observations were supported by our observations of the expression patterns of SV2. Cochlea ablation led to a reduction of SV2 expression around the somas, especially when the surgery was performed at P7 (Fig. 5), whereas the overall density of SV2 expression in the neuropil appeared to be similar to the control. Future anatomical measures using electronic microscopy are needed to determine the 
exact location of synaptic vesicles. In addition, the origin of the newly added synaptic inputs that impinge onto bushy cells as a complimentary reaction to cochlea ablation remains largely unknown. Some previous studies suggest that the contralateral bushy cells are one of the sources (Jackson and Parks 1988; Parks et al. 1990; Sumner et al. 2005). It would be also interesting to examine the time course for the effects of cochlea ablation on mEPSCs in AVCN bushy cells. Furthermore, because bushy cells also receive nonglutamate receptor-mediated synaptic inputs, it is unclear whether changes, if any, in nonglutamate synaptic vesicles after cochlea ablation contribute to this observation. Such changes have been seen in the motor system, for example, in developing mammalian motor neurons, inhibitory synaptic inputs mediated by GABA and glycine receptors play important roles in neuronal survival (Banks et al. 2005) and in axotomized motor neurons, GABAergic inputs change their sign from inhibitory to excitatory (Nabekura et al. 2002).

\section{mEPSCs and the critical period}

Various approaches have been taken to study the mechanisms underlying the critical period for mouse AVCN neurons. For example, $b c l-2$, a gene that functions as an anti-apoptotic factor and promotes cell survival, has been shown to modulate cell death in the mouse cochlear nucleus. Deletion of the gene renders mature animals $(\geq \mathrm{P} 27)$ susceptible to afferent deprivation, whereas overexpression of the gene protects AVCN neurons in young (P5/P8) animals (Mostafapour et al. 2000, 2002). Using gene microarray analysis, Harris et al. (2005) found that during and after the critical period, AVCN cells in mice differentially express genes shown to be involved in cell death or survival reported in other systems. At P7 (during the critical period), AVCN cells show relatively higher expression of six out of seven known pro-death genes. In contrast, at P14 (at the closing of the critical period) or P21 (1 wk after the critical period), AVCN cells increase the expression of 9 out of 11 genes with known pro-survival functions, including two $b c l-2$ family genes ( $b c l-x L$ and $b c l-w)$. In chickens, cochlea ablation leads to a transient increase in the expression of $b c l-2$ mRNA in a subpopulation of cochlear nucleus neurons (Wilkinson et al. 2002). It would be interesting to study in the future whether the increased level of mEPSCs in bushy cells of P14/P21 animals correlates to the increased expression of $b c l-2$ family genes or the decreased expression of pro-death genes. It is also of importance for future studies to determine the time course for mEPSC development in AVCN bushy cells after cochlea ablation performed during the critical period.

\section{A C K N OW L E D G MENTS}

We thank Drs. Thanos Tzounopoulos and Joshua Gittelman for help with the techniques to make mouse slice preparations and Dr. Sandra Bajjalieh for providing SV2 antibodies. We thank J. Gittelman, M. Howard, C. Marian, R. Papka, and J. Wenstrup for helpful discussions and comments on the manuscript. We also thank the two anonymous reviewers for comments and suggestions that greatly improved the manuscript.

$\S$ Present address of Y. Lu: Dept. of Neurobiology, Northeastern Ohio Universities College of Medicine, Rootstown, $\mathrm{OH} 44272$.

\section{G R A N T S}

Support was provided by National Institute on Deafness and Other Communications Disorders Grants DC-03829 and DC-04661.

\section{REFERENCES}

Altar CA, DiStefano PS. Neurotrophin trafficking by anterograde transport. Trends Neurosci 21: 433-437, 1998.

Banks GB, Kanjhan R, Wiese S, Kneussel M, Wong LM, O'Sullivan G, Sendtner M, Bellingham MC, Betz H, Noakes PG. Glycinergic and GABAergic synaptic activity differentially regulate motoneuron survival and skeletal muscle innervation. J Neurosci 25: 1249-1259, 2005.

Bellingham MC, Lim R, Walmsley B. Developmental changes in EPSC quantal size and quantal content at a central glutamatergic synapse in rat. J Physiol 511: 861-869, 1998.

Benson CG, Gross JS, Suneja SK, Potashner SJ. Synaptophysin immunoreactivity in the cochlear nucleus after unilateral cochlear or ossicular removal. Synapse 25: 243-257, 1997.

Brenowitz S, Trussell LO. Maturation of synaptic transmission at end-bulb synapses of the cochlear nucleus. J Neurosci 21: 9487-9498, 2001.

Brew HM, Forsythe ID. Two voltage-dependent $\mathrm{K}^{+}$conductances with complementary functions in postsynaptic integration at a central auditory synapse. J Neurosci 15: 8011-8022, 1995.

Buckley KM, Kelly RB. Identification of a transmembrane glycoprotein specific for secretory vesicles of neurons and endocrine cells. J Cell Biol 100: 1284-1294, 1985.

Cant NB. The fine structure of two types of stellate cells in the anterior division of the anteroventral cochlear nucleus of the cat. Neuroscience 6 (12): 2643-2655, 1981.

Cant NB, Morest DK. The bushy cells in the anteroventral cochlear nucleus of the cat. A study with the electron microscope. Neuroscience 4: 19251945, 1979.

Catsicas M, Pequignot Y, Clarke PG. Rapid onset of neuronal death induced by blockade of either axoplasmic transport or action potentials in afferent fibers during brain development. J Neurosci 12: 4642-4650, 1992.

Chytrova G, Johnson JE. Spontaneous retinal activity modulates BDNF trafficking in the developing chick visual system. Mol Cell Neurosci 25: 549-557, 2004.

Davies AM. The role of neurotrophins in the developing nervous system. J Neurobiol 25: 1334-1348, 1994.

Doyle WJ, Webster DB. Neonatal conductive hearing loss does not compromise brain stem auditory function and structure in rhesus monkeys. Hear Res 54: 145-151, 1991.

Fatt P, Katz B. Some observations on biological noise. Nature 166: 597-598, 1950.

Fatt P, Katz B. Spontaneous subthreshold activity at motor nerve endings. J Physiol 117: 109-128, 1952.

Ferragamo MJ, Oertel D. Functional circuitry of the cochlear nucleus: in vitro studies in slices. In: Handbook of Mouse Auditory Research. Boca Raton, FL: CRL Press, 2001, chapt. 20, p. 297-315.

Francis HW, Manis PB. Effects of deafferentation on the electrophysiology of ventral cochlear nucleus neurons. Hear Res 149: 91-105, 2000.

Frerking M, Borges S, Wilson M. Are some minis muitiquantal? J Neurophysiol 78: 1293-1304, 1997.

Galli-Resta L, Ensini M, Fusco E, Gravina A, Margheritti B. Afferent spontaneous electrical activity promotes the survival of target cells in the developing retinotectal system of the rat. J Neurosci 13: 243-250, 1993.

Gardner SM, Trussell LO, Oertel D. Time course and permeation of synaptic AMPA receptors in cochlear nuclear neurons correlate with input. J Neurosci 19: 8721-8729, 1999.

Gentschev T, Sotelo C. Degenerative patterns in the ventral cochlear nucleus of the rat after primary deafferentation. An ultrastructural study. Brain Res 62: 37-60, 1973.

Harris JA, Hardie NA, Bermingham-McDonogh O, Rubel EW. Gene expression differences over a critical period of afferent-dependent neuron survival in the mouse auditory brain stem. J Comp Neurol 493: 460-474, 2005.

Harris JA, Rubel EW. Afferent regulation of neuron number in the cochlear nucleus: cellular and molecular analyses of a critical period. Hear Res 216-217: 127-137, 2006.

Hashisaki GT, Rubel EW. Effects of unilateral cochlea removal on anteroventral cochlear nucleus neurons in developing gerbils. J Comp Neurol 283: 465-473, 1989.

Illing RB, Kraus KS, Meidinger MA. Reconnecting neuronal networks in the auditory brain stem following unilateral deafening. Hear Res 206: 185-199, 2005.

Jackson H, Parks TN. Induction of aberrant functional afferents to the chick cochlear nucleus. J Comp Neurol 271: 106-114, 1988. 
Lenn NJ, Reese TS. The fine structure of nerve endings in the nucleus of the trapzoid body and the ventral cochlear nucleus. Am J Anat 118: 375-390, 1966.

Limb CJ, Ryugo DK. Development of primary axosomatic endings in the anteroventral cochlear nucleus of mice. JARO 1: 103-119, 2000.

Magistretti J, Mantegazza M, Guatteo E, Wanke E. Action potentials recorded with patch-clamp amplifiers: are they genuine? Trends Neurosci 19: 530-534, 1996.

McKinney RA, Capogna M, Durr R, Gahwiler BH, Thompson SM. Miniature synaptic events maintain dendritic spines via AMPA receptor activation. Nat Neurosci 2: 44-49, 1999.

Moore DR. Auditory brainstem of the ferret: early cessation of development sensitivity of neurons in the cochlear nucleus to removal of the cochlea. J Comp Neurol 302: 810-823, 1990.

Mostafapour SP, Cochran SL, del Puerto NM, Rubel EW. Patterns of cell death in mouse anteroventral cochlear nucleus neurons after unilateral cochlea removal. J Comp Neurol 426: 561-571, 2000.

Mostafapour SP, del Puerto NM, Rubel EW. bcl-2 overexpression eliminates deprivation-induced cell death of brain stem auditory neurons. $\mathrm{J} \mathrm{Neu}$ rosci 22: 4670-4674, 2002.

Nabekura J, Ueno T, Okabe A, Furuta A, Iwaki T, Shimizu-Okabe C, Fukuda A, Akaike N. Reduction of $\mathrm{KCC} 2$ expression and $\mathrm{GABA}_{\mathrm{A}}$ receptor-mediated excitation after in vivo axonal injury. J Neurosci 22: 44124417, 2002.

Oertel D. The role of timing in the brain stem auditory nuclei of vertebrates. Anпи Rev Physiol 61: 497-519, 1999.

Oleskevich S, Walmsley B. Synaptic transmission in the auditory brainstem of normal and congenitally deaf mice. J Physiol 540: 447-455, 2002.

Otsu Y, Murphy TH. Miniature transmitter release: accident of nature or careful design? Sci STKE pe54, 2003.

Parks TN, Taylor DA, Jackson H. Adaptations of synaptic form in an aberrant projection to the avian cochlear nucleus. J Neurosci 10: 975-984, 1990.

Rall W. Distinguishing theoretical synaptic potentials computed for different soma-dendritic distributions of synaptic input. J Neurophysiol 30: $1138-$ $1168,1967$.

Rall W, Burke RE, Smith TG, Nelson PG, Frank K. Dendritic location of synapses and possible mechanisms for the monosynaptic EPSP in motoneurons. J Neurophysiol 30: 1169-1193, 1967.

Rinzel J, Rall W. Transient response in a dendritic neuron model for current injected at one branch. Biophys J 14: 759-790, 1974.

Rubel EW, Fritzsch B. Auditory system development: primary auditory neurons and their targets. Anпи Rev Neurosci 25: 51-101, 2002.
Ryugo DK, Rosenbaum BT, Kim PJ, Niparko JK, Saada AA. Single unit recordings in the auditory nerve of congenitally deaf white cats: morphological correlates in the cochlea and cochlear nucleus. J Comp Neurol 397: 532-548, 1998.

Sara Y, Virmani T, Deak F, Liu X, Kavalali ET. An isolated pool of vesicles recycles at rest and drives spontaneous neurotransmission. Neuron 45: 563-573, 2005.

Sharma G, Vijayaraghavan.Modulation of presynaptic store calcium induces release of glutamate and postsynaptic firing. Neuron 38: 929-939, 2003.

Smith PH, Rhode WS. Structural and functional properties distinguish two types of multipolar cells in the ventral cochlear nucleus. J Comp Neurol 282: 595-616, 1989.

Sumner CJ, Tucci DL, Shore SE. Responses of ventral cochlear nucleus neurons to contralateral sound after conductive hearing loss. J Neurophysiol 94: 4234-4243, 2005.

Sutton MA, Wall NR, Aakalu GN, Schuman EM. Regulation of dendritic protein synthesis by miniature synaptic events. Science 304: 1979-1983, 2004.

Tierney TS, Russell FA, Moore DR. Susceptibility of developing cochlear nucleus neurons to deafferentation-induced death abruptly ends just before the onset of hearing. J Comp Neurol 378: 295-306, 1997.

Trune DR, Morgan CR. Influence of developmental auditory deprivation on neuronal ultrastructure in the mouse anteroventral cochlear nucleus. Dev Brain Res 42: 304-308, 1988.

Trussell LO. Synaptic mechanisms for coding timing in auditory neurons. Annu Rev Physiol 61: 477-496, 1999.

Tucci DL, Born DE, Rubel EW. Changes in spontaneous activity and CNS morphology associated with conductive and sensorineural hearing loss in chickens. Ann Otol Rhinol Laryngol 96: 343-350, 1987.

Tzounopoulos T, Kim Y, Oertel D, Trussell LO. Cell-specific, spike timingdependent plasticities in the dorsal cochlear nucleus. Nat Neurosci 7: 719-725, 2004

Wilkinson BL, Sadler KA, Hyson RL. Rapid deafferentation-induced upregulation of bcl-2 mRNA in the chick cochlear nucleus. Brain Res Mol Brain Res 99: 67-74, 2002.

Wang Y, Manis PB. Synaptic transmission at the cochlear nucleus endbulb synapse during age-related hearing loss in mice. J Neurophysiol 94: 1814$1824,2005$.

Wu SH, Oertel D. Maturation of synapses and electrical properties of cells in the cochlear nuclei. Hear Res 30: 99-110, 1987.

Young ED, Oertel D.Cochlear nucleus. In: The Synaptic Organization of the Brain (5th ed.), edited by Shepherd GM. Oxford, UK: Oxford Univ. Press, 2004, chapt. 4, p. 125-163. 